C) Copyright 2018: Editum. Servicio de Publicaciones de la Universidad de Murcia. Murcia (Spain) ISSN print edition: 0212-9728. ISSN on line edition (http://revistas um es/analesps): 1695-2294. On line edition License Creative Commons 4.0: BY-NC-ND

\title{
Two new brief versions of the Cognitive Emotion Regulation Questionnaire and its relationships with depression and anxiety
}

\author{
Fco. Pablo Holgado-Tello*, Pedro J. Amor, Amaia Lasa-Aristu, Fco. Javier Domínguez-Sánchez, and Begoña Delgado
}

Universidad Nacional de Educación a Distancia - UNED (Spain).

\begin{abstract}
Título: Dos nuevas versiones breves del Cognitive Emotion Regulation Questionnaire y su relación con la depresión y ansiedad

Resumen: El Cognitive Emotion Regulation Questionnaire (CERQ) (Garnefski, et al., 2001) es un instrumento de 36 ítems que mide las estrategias cognitivas de la regulación emocional. Hay una versión breve de 18 elementos que mide las mismas nueve estrategias que la versión completa (Garnefski y Kraaij, 2006a). El objetivo de este estudio fue desarrollar una versión breve, teniendo en cuenta dos propuestas: un instrumento de 27 ítems y otro de 18 , el cual se centra exclusivamente en la evaluación de los dos factores generales obtenidos en la estructura de segundo orden del CERQ original e identificado en estudios previos como estrategias adaptativas y estrategias menos adaptativas. Los participantes en el estudio fueron 872 personas de 18 a 58 años $(M=33.86 ; D T=8.43)$. El análisis factorial confirmatorio, proporciona índices globales adecuados en ambas versiones, junto con una validez satisfactoria. En la discusión, se argumenta que la versión de 27 ítems es más apropiada para la evaluación específica de las nueve estrategias de regulación que emplean las personas, y proponemos la versión de 18 ítems como un instrumento adecuado en el contexto clínico para una calificación global del perfil de regulación emocional cognitiva, además, la validez de criterio con depresión y ansiedad se mantiene similar a las versiones completas.
\end{abstract}

Palabras clave: Cognitive Emotion Regulation Questionnaire, versiones breves, depresión, ansiedad.

\section{Introduction}

Emotion is a multicomponent process that is activated when relevant circumstances for the person occur, implementing action tendencies that facilitate the deployment of adapted behaviors (Scherer, 2009).

An essential element of this process is emotional regulation, which permits modulation of the suitability of the emotion itself, but also that of each one of the components making it up (Scherer, 2009). This dynamic involves widely heterogeneous processes, including those of a cognitive nature, understood as a set of information-processing strategies or mechanisms that allow the person to regulate different parameters of his or her emotional reactions (Thompson, 1991). These cognitive strategies are not only relevant in the maintenance of an appropriate level of psychological wellbeing (Gross \& Muñoz, 1995), but can also constitute important factors in the aetiology and chronification of certain psychopathological disorders (e.g., Garnefski \& Kraaij, 2006a), as well as in the efficacy of therapeutic intervention (Goldin et al., 2012).

A key factor in the studies carried out in this field has been the availability of a psychometric instrument that per-

* Correspondence address [Dirección para correspondencia]: Fco. Pablo Holgado-Tello. Dpto. Methodology of the Behavioral Sciences. Faculty of Psychology. UNED. c/Juan del Rosal, n ${ }^{\circ}$ 10. 28040 Madrid (Spain). E-mail: pfholgado@psi.uned.es
Abstract: The Cognitive Emotion Regulation Questionnaire (CERQ) (Garnefski et al., 2001) is a 36-item instrument for measuring cognitive strategies of emotional regulation. There is a brief, 18 -item version that measures the same nine strategies as the full version (Garnefski \& Kraaij, 2006a). The aim of this study was to develop a brief form of the CERQ, taking into account two different proposals: a 27 -item and an 18 -item instrument, the latter focusing solely on the assessment of the two general factors obtained in the second-order structure of the original CERQ model and identified in previous studies as adaptive strategies and less adaptive strategies. Participants in the study were 872 individuals aged $18-58(M=33.86$, $S D=8.43)$. The confirmatory factor analyses yield adequate overall indices in both versions, together with satisfactory validity. In the discussion, it is argued that the 27 -item version is more appropriate for the specific rating of the nine regulation strategies people employ, and we propose the 18item version as a suitable instrument in clinical context for an overall rating of an individual's cognitive emotion regulation profile, furthermore, the criterion validity with depression and anxiety keeps similar to the larger versions.

Keywords: Cognitive Emotion Regulation Questionnaire, short versions, depression, anxiety.

mits assessment of these cognitive strategies, the CERQ. This questionnaire, developed by Garnefski, Kraaij, and Spinhoven (2001), consists of 36 items, four for each of the nine cognitive emotion regulation strategies it measures: Self-blame (i.e., thinking that one is responsible for what happened), Acceptance (i.e., accepting what has happened and resigning oneself to it), Rumination (i.e., reflecting on one's feelings and thoughts associated with what happened), Positive refocusing (i.e., thinking about enjoyable experiences instead of about the stressful event), Refocus on planning (i.e., concentrating on the measures to adopt in response to the event), Positive reappraisal (i.e., considering the positive aspects of what happened), Putting into perspective (i.e., reducing the relevance of the event), Catastrophizing (i.e., having thoughts that intensify the negative side of what happened), and Blaming others (i.e., having thoughts that shift the blame for what happened to us onto others). In turn, these nine scales can be grouped in two, more general categories: adaptive (theoretically more appropriate strategies, understood as positive-focused cognitive emotion regulation: Acceptance, Positive refocusing, Refocus on planning, Positive reappraisal, Putting into perspective) and less adaptive (theoretically more inappropriate strategies, understood as negative-focused cognitive emotion regulation: Selfblame, Rumination, Catastrophizing, Blaming others). The use of the less adaptive strategies is related with psychopathological symptomatology. Self-blame, Rumination and Catastrophizing are related to anxiety and depression (Gar- 
nefski \& Kraaij, 2006b). Conversely, the frequently use of the adaptive strategies protects against these symptoms (Kraaij et al., 2003; d'Acremont \& van der Linden, 2007). In this sense, the assessment of both strategies is key to the implementation of prevention and intervention programs.

The CERQ has good psychometric properties, both in its original version (Garnefski et al., 2001) and in the various translated versions, in which the structure of the original nine-factor model has been confirmed (DomínguezSánchez, Lasa-Aristu, Amor, \& Holgado-Tello, 2013; Jermann, van der Linden, d'Acremont, \& Zermatten, 2006; Zhu et al., 2008). Furthermore, this questionnaire has emerged as a valuable instrument in the applied context, facilitating the identification of intervention objectives, and providing a means of evaluating individual risk and protective factors in the response to emotionally conflictive or stressful situations (Garnefski \& Kraaij, 2006b; Garnefski \& Kraaij, 2007).

Recently, Garnefski and Kraaij (2006a) developed a brief version of the CERQ with 18 items, so that each of the nine original scales is assessed through two items. Despite this reduction in the number of items, the questionnaire maintains both the factor structure and the good psychometric properties (alpha indices of between .68 [self-blame] and .81 [positive reappraisal and catastrophizing]) of the original instrument (Garnefski \& Kraaij, 2006a).

Notwithstanding the above, in the psychometric literature it is argued that there are substantial metric limitations which make it inadvisable for any latent variable to be measured by just two items (Kruyen, 2012). This condition, present in the brief version of the CERQ, seriously threatens the construct validity (e.g., under-representation of the construct, mono-operation bias, confusion of constructs) (Kruyen, Emons, \& Sijtsma, 2013; Shadish, Cook, \& Campbell, 2002). Likewise, a reduction to 18 items compromises the specification of models via Confirmatory Factor Analysis, since a model made up of a single latent variable measured with only two indicators implies a sub-identified model, which is therefore of no metric interest (Jöreskog \& Sörbom, 1996). Therefore, although the brief version of the CERQ has shown itself to be useful in practice, this instrument has certain psychometric limitations that could affect its construct validity.

The Spanish version of the original 36-item questionnaire, called CERQ-S (Domínguez-Sánchez et al., 2013), also presents good psychometric characteristics, and reflects the same first and second-order structures observed in the original CERQ model. The main objective of the present study is to develop two brief versions of the CERQ-S, which would permit the rapid and effective assessment of cognitive emotion regulation strategies, but taking into account the psychometric requirements referred to above. For this purpose we set out to construct two versions with two different aims, a first version with 27 items, designed to assess the nine original dimensions of the model (with at least of three items by each factor to preserve some relevant metric crite- rion), and a second version comprising 18 items and designed to measure only the two higher-order factors obtained in the original model - "adaptive strategies" versus "less adaptive strategies". The two solutions address different assessment objectives, and in either case the idea is that the length of the instrument will make it possible to guarantee conceptual equivalence with the original model. Finally, the psychometric properties of the solutions obtained will be examined.

\section{Methodology}

\section{Participants}

Participants in this study were 872 people aged between 18 and $58(M=33.86, S D=8.43)$. Nineteen per cent of the participants were men (mean age $35.77, S D=8.09$ ) and $81 \%$ were women (mean age 33.42, $S D=8.45$ ). As regards employment status, the breakdown was as follows: $54 \%$ were in a regular job, $17 \%$ were in temporary employment, $14.2 \%$ were officially unemployed and $14.6 \%$ were exclusively studying.

\section{Procedure}

Selection of the sample was by means of a personal email. In this e-mail, potential participants were told that participation was voluntary and anonymous, involved no type of financial or academic reward, and that it consisted in filling out a battery of questionnaires that could be found on an Internet website accessed by means of a username and password.

\section{Instruments}

Cognitive Emotion Regulation Questionnaire (CERQ; Garnefski et al., 2001; Spanish version by Domínguez-Sánchez et al., 2013). It consists of nine scales with 4 items each. The scales have been described in detail in the introduction section. Response to the items is on a Likert-type scale where 1 $=$ "almost never" and $5=$ "almost always". Internal consistency (Cronbach's alpha) of the different dimensions for the sample studied ranges from .62 (Acceptance) to .90 (Positive refocusing).

Beck Depression Inventory (BDI; Beck, Rush, Shaw, \& Emery, 1979; Spanish version by Vázquez \& Sanz, 1997). This is a 21 -item self-report (range: 0 - 63 points) that measures the intensity of depressive symptoms. The reliability coefficient obtained by the two-halves method is .93 . From the perspective of convergent validity, correlation with the clinical assessment of depression ranges from .62 to .66.

State-Trait Anxiety Inventory (STAI; Spielberger, Gorsuch, \& Lushene, 1970; Spanish version by TEA, 1982). This is a self-report instrument with 20 items related to Trait Anxiety and another 20 related to State Anxiety; score range is 0 to 60 points for each scale. In the present study we used the 
STAI-T (Trait), whose Spanish version has a test-retest reliability of .81 and an internal consistency ranging from .83 to .92 .

State-Trait Anger Expression Inventory-2 (STAXI-2; Spielberger, 1988; Spanish version by Miguel-Tobal, Casado, Cano-Vindel, \& Spielberger, 2001). In the present study we used the Trait anger scale, which comprises 10 items (range of 0-40 points); it has a test-retest reliability of .71 and an internal consistency of .89 .

Positive and Negative Affect Schedule (PANAS; Watson, Clark, \& Tellegen, 1988; Spanish version by Sandín et al., 1999). This is a 20-item instrument for the assessment of two independent dimensions: Positive Affect (AP) and Negative Affect (NA). Range for each scale is from 10 to 50 points (10 items in each scale). Internal consistency is in the range .87 to .91 , and the remaining psychometric properties are quite satisfactory.

\section{Statistical analysis}

It was deemed appropriate to divide the total sample of 872 randomly but equally in two subsamples, $\mathrm{A}$ and $\mathrm{B}$. In a first step we extracted the 27 items that saturated most from the 36-item model, to subsequently verify the fit of this new model and the data with one of the subsamples (A). In a second step, of the 27 items we extracted the 18 that saturated most, subsequently verifying the model with the subsample B. This cross-validation procedure was employed in an effort to avoid the problem of random capitalization, so that the generalization of the model is optimized through the use of different subsamples (Cudeck \& Browne, 1983). In either case we used the Confirmatory Factor Analysis (CFA) procedure, employing polychoric correlations, and unweighted least squares (ULS) as estimation method, given the ordinal nature of the data (Yang-Wallentin, Jöreskog, \& Luo, 2010).

Likewise, through Steiger's Z-test for dependent correlations we analyzed the differences of correlations between the dimensions of the 36 and 27-item models with the scores obtained in the depression, anxiety, anger, and positive and negative affect questionnaires.

The statistical programs used were SPSS 15.0 for Windows and LISREL 8.71 (Jöreskog \& Sörbom, 1996).

\section{Results}

\section{Initial extraction of 27 items grouped in 9 dimen- sions}

Following the procedure used by Garnefski and Kraaij (2006b) in the construction of the brief version of the instrument, in a first step we made reliability analyses of the nine scales. Eliminating from each one of them the item whose removal ameliorated the scale's Cronbach's alpha value the most, we obtained a first group of 27 items (three items per dimension). The 27 items with the highest saturations in the 36-item model were: Self-blame (items 1, 10 and 28), Acceptance (items 2, 11 and 29), Rumination (items 3,
12 and 30), Positive refocusing (items 4, 13 and 22), Refocus on planning (items 14, 23 and 32), Positive reappraisal (items 15, 24 and 33), Putting into perspective (items 16, 25 and 34), Catastrophizing (items 17, 26 and 35) and Blaming others (items 9, 18 and 36).

Once we had selected the 27 items with the highest factor loadings in the 36-item model, and which in turn were those with the best discriminatory capacity, we subjected the model (Model 1) to a CFA in subsample A. The estimation method used was ULS. Table 1 shows the completely standardized solution, as well as the correlations between the factors. The overall goodness of fit indices obtained for Model

Table 1. CERQ-S-27. Completely standardized solution of Model 1 (subsample A).

\begin{tabular}{|c|c|c|c|c|c|c|c|c|c|}
\hline Item & SB & Acc & Rum & P-Ref & R-Pla & P-Rea & $\mathrm{PP}$ & Cat & $\mathrm{BO}$ \\
\hline i1 & .65 & & & & & & & & \\
\hline i10 & .57 & & & & & & & & \\
\hline i28 & .64 & & & & & & & & \\
\hline i2 & & .64 & & & & & & & \\
\hline i11 & & .73 & & & & & & & \\
\hline i29 & & .53 & & & & & & & \\
\hline i3 & & & .39 & & & & & & \\
\hline i12 & & & .51 & & & & & & \\
\hline i30 & & & .76 & & & & & & \\
\hline i4 & & & & .90 & & & & & \\
\hline i13 & & & & .98 & & & & & \\
\hline i22 & & & & .96 & & & & & \\
\hline i14 & & & & & .73 & & & & \\
\hline $\mathrm{i} 23$ & & & & & .64 & & & & \\
\hline i32 & & & & & .67 & & & & \\
\hline i15 & & & & & & .91 & & & \\
\hline i24 & & & & & & .69 & & & \\
\hline $\mathrm{i} 33$ & & & & & & .89 & & & \\
\hline i16 & & & & & & & .77 & & \\
\hline $\mathrm{i} 25$ & & & & & & & .90 & & \\
\hline $\mathrm{i} 34$ & & & & & & & .69 & & \\
\hline i17 & & & & & & & & .70 & \\
\hline $\mathrm{i} 26$ & & & & & & & & .62 & \\
\hline i35 & & & & & & & & .72 & \\
\hline i9 & & & & & & & & & .81 \\
\hline i18 & & & & & & & & & .76 \\
\hline $\mathrm{i} 36$ & & & & & & & & & .97 \\
\hline Acc & -.12 & & & & & & & & \\
\hline Rum & .25 & -.14 & & & & & & & \\
\hline P-Ref & -.14 & .36 & -.16 & & & & & & \\
\hline R-Pla & -.18 & .47 & -.21 & .54 & & & & & \\
\hline P-Rea & -.19 & .50 & -.22 & .57 & .75 & & & & \\
\hline PP & -.16 & .41 & -.18 & .48 & .62 & .66 & & & \\
\hline Cat & .53 & -.29 & .61 & -.33 & -.43 & -.46 & -.38 & & \\
\hline BO & .13 & -.07 & .14 & -.08 & -.01 & -.11 & -.09 & .30 & \\
\hline $\mathrm{F}+$ & & .56 & & .64 & .84 & .89 & .74 & & \\
\hline F- & .47 & & .54 & & & & & .85 & .27 \\
\hline
\end{tabular}

Note: $\mathrm{SB}=$ Self-Blame; Acc $=$ Acceptance; Rum $=$ Rumination; P-Ref $=$ Positive Refocus; R-Pla $=$ Refocus on Planning; P-Rea $=$ Positive Reappraisal; $\mathrm{PP}=$ Putting into Perspective; Cat $=$ Catastrophizing; $\mathrm{BO}=$ Blaming Others. $\mathrm{F}+=$ Adaptive strategies; $\mathrm{F}-\mathrm{=}$ Less adaptive.

1 were: $\chi^{2}(d f=314 ; p=.0001)=587.47$; RMSEA $=.049$ with an interval at $90 \%$ from .043 to .055 ; SRMR $=.87$; NFI $=.89 ; \mathrm{CFI}=.95 ; \mathrm{GFI}=.96 ;$ and $\mathrm{AGFI}=.95$. That is, the 
measurement values obtained with the 27 -item instrument are reasonably close to those of the classic CERQ model, made up of 9 basic dimensions and two second-order factors.

\section{Extraction of 18 items grouped in two dimensions}

To obtain the brief, 18-item version, following the above procedure, we selected from the 27 -item version the 18 items with the highest saturations in the 36 -item model and the best discriminatory capacity: $1,10,3,12,17,35,9,18,2$, $11,13,22,14,32,24,33,25$ and 34 .

Once the 18 items had been identified, we proceeded to confirm in subsample B a model (Model 2) made up of the 18 items with the best psychometric properties. To avoid the problem of under-representation of the construct, as well as technical problems of statistical identification, we proposed a first-order factor structure on the basis of the two general (second-order) factors identified in previous studies: adaptive strategies and less adaptive strategies (Domínguez-Sánchez et al., 2013; Garnefski et al., 2001; Jermann et al., 2006). This permitted the saturation of the 10 items corresponding to the dimensions Acceptance, Positive refocusing, Refocus on planning, Positive reappraisal and Putting into perspective, in the dimension "Adaptive strategies"; the 8 items corresponding to the dimensions Self-blame, Rumination,
Catastrophizing and Blaming others went to make up the dimension "Less adaptive strategies".

The model proposed (Model 2) yielded the following overall fit indices: $\chi^{2}(d f=134 ; p=.0001)=459.15$; RMSEA $=.085$ with an interval at $90 \%$ from .070 to .099 ; SRMR $=$ $.11 ; \mathrm{NFI}=.83 ; \mathrm{CFI}=.90 ; \mathrm{GFI}=.90 ;$ and $\mathrm{AGFI}=.87$.

Given these results, there would be sources of discrepancy that make it unviable to accept the null hypothesis on the suitability of the model. Therefore, we turned to modification indices to identify such discrepancies. It was found that if the model was made to include the correlation between the errors of items 2 and 11 (Acceptance dimension), the fit would improve considerably. Therefore, we proceeded to test a new model (Model 3) that included the estimation of this parameter. The goodness of fit indices of Model 3 are: $\chi^{2}(d f=133 ; p=.0001)=396.87 .15$; RMSEA $=.073$ with an interval at $90 \%$ from .058 to .088 ; SRMR $=.10$; NFI $=.85$; CFI $=.93$; GFI $=.91$; and $\mathrm{AGFI}=.89$. This new model yielded a significant increase in $\chi^{2}$ of 62.28 for one degree of freedom. This result, together with the overall goodness of fit indices, permits us to conclude that the fit of Model 3 is acceptable. The completely standardized solution for Model 3 is shown in Figure 1.

In the Table 2, the fit indices for the models and the increase in Chi-square test (model 3 respects to model 2) are summarized.

Table 2. Fit indices.

\begin{tabular}{ccccccccccc}
\hline Model (sample) & RMSEA & GFI & AGFI & SRMR & NFI & CFI & $\chi^{2}$ & $d f$ & $\Delta \chi^{2}$ & $\Delta d f$ \\
\hline (1(A) & .049 & .96 & .95 & .87 & .89 & .95 & 587.47 & 314 & \\
\hline 2(B) & .085 & .90 & .87 & .11 & .83 & .90 & 459.15 & 134 & \\
3(B) & .073 & .91 & .89 & .10 & .85 & .93 & 396.87 & 133 & 62.28 & 1 \\
\hline
\end{tabular}

Note: RMSEA $=$ root mean square error of approximation; GFI $=$ goodness of fit index; AGFI $=$ adjusted GFI; SRMR $=$ standardised root mean square residual; $\mathrm{NFI}=$ normed fit index; $\mathrm{CFI}=$ comparative fit index; $\Delta \chi^{2}=$ increment of $\chi^{2} ; \Delta d f=$ increment of $d f$.

In order to artificially increase model fit, correlations between the errors are usually included. This is certainly an inappropriate practice, but in this particular case we understand that there is a problem carried forward from the original model in which the Acceptance dimension (DomínguezSánchez et al., 2013; Garnefski et al., 2001) is not measured accurately, probably due to the fact that the number of items is insufficient to define it in a relevant and representative manner. This shortcoming is exacerbated when the number of items in the Acceptance dimension is reduced by half, and since this dimension does not exist in Model 3 as a latent variable, the common variability of the two items is transferred to the error terms.

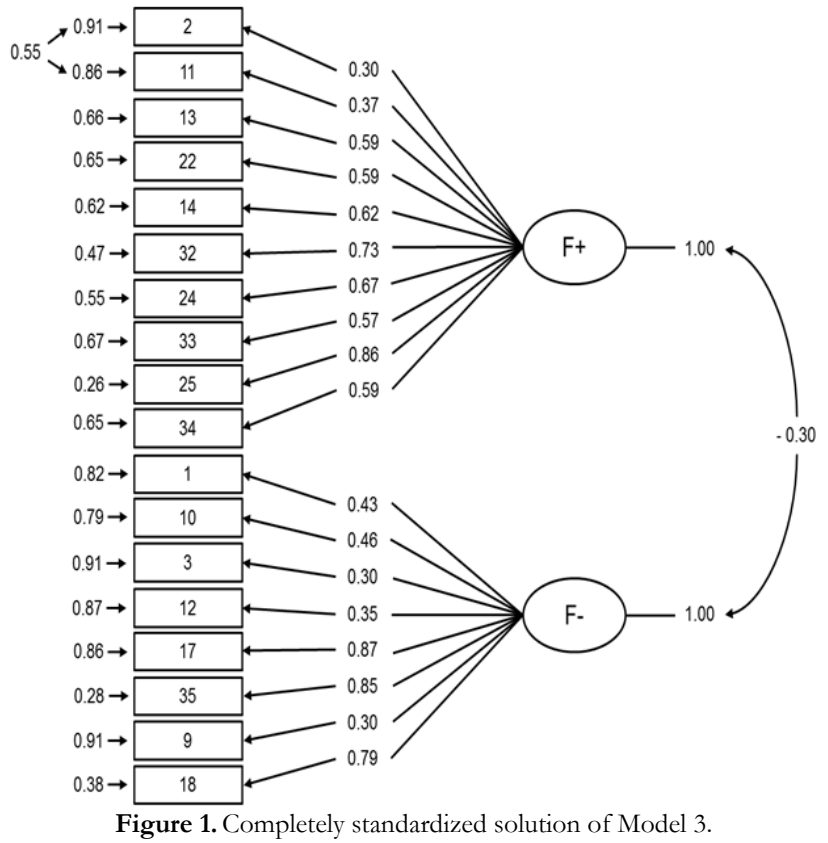

anales de psicología / annals of psychology, 2018, vol. 34, $\mathrm{n}^{\circ} 3$ (october) 


\section{Psychometric characteristics of the dimensions}

Table 3 shows the psychometric characteristics of the dimensions of the 36-, 27- and 18-item models. This table includes the means and standard deviations of the different dimensions in each one of the models so as to facilitate the comparison. No mean differences between dimensions were found.

Table 3. Basic psychometric properties of the CERQ-S, CERQ-S-27 and CERQ-S-18.

\begin{tabular}{|c|c|c|c|c|c|c|c|c|c|c|c|}
\hline & \multicolumn{11}{|c|}{ CERQ-36 } \\
\hline Dimensions & SB & Acc & Rum & P-Ref & $\mathrm{R}-\mathrm{Pla}$ & P-Rea & $\mathrm{PP}$ & Cat & $\mathrm{BO}$ & Adap & $\overline{\text { Less }}$ \\
\hline Mean & 2.67 & 3.34 & 3.31 & 2.77 & 3.85 & 3.86 & 3.47 & 1.97 & 1.91 & 3.15 & 2.61 \\
\hline$S D$ & .70 & .78 & .89 & 1.05 & .78 & .86 & .94 & .73 & .62 & .51 & .56 \\
\hline Asymmetry & .661 & -.058 & -.118 & .364 & -.555 & -.646 & -.235 & .906 & 1.10 & -.16 & -.16 \\
\hline Kurtosis & .729 & -.560 & .583 & -.644 & -.146 & -.183 & -.697 & .637 & 2.68 & .43 & -.23 \\
\hline Cronbach's alpha & .65 & .62 & .74 & .90 & .78 & .83 & .80 & .70 & .79 & .89 & .78 \\
\hline \multirow[t]{2}{*}{ Mean discrimination } & .40 & .41 & .53 & .76 & .59 & .49 & .66 & .52 & .61 & .50 & .36 \\
\hline & \multicolumn{11}{|c|}{ CERQ-27 } \\
\hline Mean & 2.25 & 3.63 & 3.22 & 2.67 & 3.9 & 3.74 & 3.57 & 1.97 & 1.79 & 3.01 & 2.60 \\
\hline$S D$ & .81 & .91 & .95 & 1.08 & .86 & 1.02 & .66 & .78 & .63 & .53 & .59 \\
\hline Asymmetry & .960 & -.223 & -.001 & .446 & -.614 & -.559 & -.362 & 1.01 & 1.15 & -.14 & -.01 \\
\hline Kurtosis & 1.03 & -.800 & -.743 & -.602 & -.227 & -.581 & -.722 & .832 & 2.94 & .31 & -.04 \\
\hline Cronbach's alpha & .74 & .72 & .73 & .88 & .79 & .83 & .80 & .73 & .84 & .88 & .79 \\
\hline \multirow[t]{2}{*}{ Mean discrimination } & .57 & .55 & .55 & .78 & .63 & .61 & .65 & .57 & .72 & .52 & .42 \\
\hline & \multicolumn{11}{|c|}{ CERQ-18 } \\
\hline
\end{tabular}

Mean

SD

AdaptiveLess adaptive

Asymmetry

$3.50 \quad 2.38$

Kurtosis

Cronbach's alpha

$.731-.56$

$-.262 \quad .349$
-.208

$-.208-.081$

Mean discrimination

$.84 \quad .72$

Note: SB = Self-Blame; Acc = Acceptance; Rum = Rumination; P-Ref = Positive Refocus; R-Pla = Refocus on Planning; P-Rea = Positive Reappraisal; PP = Putting into Perspective; Cat $=$ Catastrophizing; $\mathrm{BO}=$ Blaming Others.

With the aim of examining the equivalence of the criterion validity indices (correlations between emotion regulation factors and criterion variables) of the original instrument with those of the brief 27 -item version, we carried out significant tests for differences of correlations between those obtained in the two versions.

After examining the differences between each pair of correlations (45) of the dimensions of the 36-item CERQ-S and the 27-item CERQ-S (Model 1) and the values of the depression (BDI), trait anxiety (STAI-T), trait anger (STAXI-2-T) and positive (PA) and negative affect (NA) scales - except for Self-blame and BDI $(z=-2.03, p<.042)$ and Self-blame and STAI-R $(z=-2.01, p<.044)$, which emerged as significant - we found no statistically significant differences at a $95 \%$ confidence level. If we consider a confidence level of $99 \%$ there would be no statistically different correlations comparison.

\section{Discussion}

The purpose of the present study was to construct a brief form of the Spanish version of the CERQ through the comparison of two different proposals: A first proposal made up of 27 items (CERQ-S-27) and a second one made up of 18 items (CERQ-S-18). The results show that both versions present appropriate psychometric indices and good fit. The- se condensed versions optimize not only the administration of the instrument, but also its psychometric properties. They have been purged of those items which, for various reasons (negative contribution to the reliability of the dimension, lower discriminatory capacity, cultural bias, etc.), led to difficulties with the original Spanish questionnaire (e.g., items 19, 20 and 21 of the CERQ-S).

With respect to the original instrument, the CERQ-S-27 questionnaire brings about a reduction of one item for each dimension. Thus, in the CERQ-S-27 each cognitive strategy is assessed by means of three items, instead of the four used in the full versions. This reduction is still in line with the norms of confirmatory factor analysis, which include the requirement of using at least three items per latent variable (Jöreskog \& Sörbom, 1996). The CERQ-S-27 fits with the 9 basic dimensions of the factor structure of the original instrument. The results of the CFA reveal a factorially defined distribution of the trios of items in the conceptual subscales (Table 1). In general, the reliability of these scales remains around the values observed in the full version (Table 3). Indeed, it improves notably in the cases of the Self-blame and Acceptance subscales -an effect which can be attributed to the purging of conflictive items of the original CERQ.

Furthermore, empirical evidence is contributed for the equivalence of the criterion validity coefficients between the two versions, and this undoubtedly supports the good psy- 
chometric behaviour of the 27-item version, insofar as it predicts anxiety and depression symptoms with the same predictive power as the original version. That is, the criterion validity coefficients are not statistically different from those of the original version, except for Self-blame and both BDI and STAI-T. This result could be due to an optimization in the reliability of Self-blame measure in the 27 items version. Removal of item 19, results in a higher correlation between Self-blame and both emotional problem indicators.

On the other hand, the fact that the CERQ-S-18 employs just two items for assessing each dimension means that it is at odds with the psychometric requirements referred to above. In fact, in the 18-item instrument we find the phenomenon of "superficial similarity" with respect to that of 36 items; that is, the measurement reliability of each factor is maintained or even increased, but there is no guarantee of the representativeness of the construct to be measured. In sum, an instrument with these characteristics is not psychometrically suitable for the assessment of the 9 conceptual strategies. A consequence of this may be the need to correlate the errors of items 2 and 11 . There is common variability in the error terms of these items resulting from a common factor, which is not explicitly included in the mod$\mathrm{el}$, and this is probably due to the fact that the Acceptance dimension is not well represented. Indeed, it is the factor with the highest random error in the 36-item model $(\alpha=$ $.62)$, and hence that which is least well defined in the 18item model. In our understanding, it is a consequence of the threat to the construct validity referred to as underrepresentation of the construct, which in this case has become apparent through the correlation of the errors of its items. That is, Acceptance is a dimension that requires more elements to be measured with the same validity and reliability than other. In this sense a recent meta-analysis carried out by Sakakibara and Kitahara (2016) indicate that acceptance had significantly positive correlations with both depression and anxiety.

Nevertheless, these limitations can be sidestepped by modifying the measurement target. Thus, in our study, instead of focusing on the nine genuine coping strategies, the purpose of the instrument becomes the assessment of the overall functionality of these strategies, categorized as "adaptive" and "less adaptive". This modification ensures sufficient sampling of each of the two dimensions to be meas-

\section{References}

Aldao, A. \& Nolen-Hoeksema, S. (2012). The influence of context on the implementation of adaptive emotion regulation strategies. Behaviour Research and Therapy, 50, 493-501. doi: 10.1016/j.brat.2012.04.004.

Beck, A. T., Rush, A. J., Shaw, B. F., \& Emery, G. (1979). Cognitive therapy of depression. New York: Guilford Press.

Cudeck, R., \& Browne, M.W. (1983). Cross-validation of covariance structures. Multivariate Behavioral Research, 18, 147-167. doi:10.1207/s15327906mbr1802_2

d'Acremont, M. \& Van der Linden, M. (2007). How is impulsivity related to depression in adolescence? Evidence from a French validation of the ured, thus safeguarding the construct validity of the instrument, at the same time as improving its reliability. Moreover, as in the case of the CERQ-S-27, the criterion validity coefficients do not differ significantly from those of the full version.

In sum, in the present work we have developed two brief forms of the CERQ-S offering different benefits and providing sufficient guarantees of their reliability and construct validity. The CERQ-S-27 permits a detailed evaluation of the profile of cognitive strategies. It is therefore a useful instrument in both basic research studies and clinical assessment. Furthermore, the CERQ-S-18 makes possible an overall analysis of the individual profile of cognitive coping with these types of situation, so that it can be considered appropriate as an instrument in field studies (e.g., natural disasters, violent acts, emergency situations) or as a clinical tool for screening or rapid assessment. When the measure is used with intervention purposes, the interpretation of the assessment data should be complemented with the functional analysis of the contexts in which the person uses the strategies (Aldao \& Nolen-Hoeksema, 2012).

In any case, on using these two new versions of the CERQ-S it should be borne in mind that the instrument was originally designed and constructed for the assessment of cognitive emotion regulation strategies in relation to a particular range of emotional experiences. This indeed means that the instrument's construct validity is limited to these types of situations, so that the measurement of these 9 strategies is guaranteed exclusively in such contexts, and not in relation to other aspects of the affective dimension less clearly characterized by a sense of threat or a person's reaction to conflict or stress.

Finally, some limitations of this study should be considered. The measures adopted for safeguarding the psychometric equivalence between the original instrument and its two brief versions do not preclude possible effects of other factors, which could affect the accuracy and overall validity of both brief tests, and which merit further study. Furthermore, given that the CERQ's purpose is to assess the coping resources a person uses not only at a given point in time but also longitudinally, it would be useful to assess the level of sensitivity to change of each of the short versions proposed here.

Cognitive Emotion Regulation Questionnaire. Journal of Adolescence, 30, 271-282. doi:10.1016/j.adolescence.2006.02.007

Domínguez-Sánchez, F. J., Lasa-Aristu, M. Amor, P. J., \& Holgado-Tello, F. P. (2013). Psychometric properties of the Spanish version of the Cognitive Emotion Regulation Questionnaire. Assessment, 20, 253-261. doi:10.1177/1073191110397274

Garnefski, N., \& Kraaij, V. (2006a). Cognitive emotion regulation questionnaire - development of a short 18-item version (CERQ-short). Personality and Individual Differences, 41, 1045-1053. doi:10.1016/j.paid.2006.04.010 
Garnefski, N., \& Kraaij, V. (2006b). Relationships between cognitive emotion regulation strategies and depressive symptoms: A comparative study of five specific samples. Personality and Individual Differences, 40, 1659-1669. doi:10.1016/j.paid.2005.12.009

Garnefski, N., \& Kraaij, V. (2007). The Cognitive Emotion Regulation Questionnaire: Psychometric features and prospective relationships with depression and anxiety in adults. European Journal of Psychological Assessment, 23, 141-149. doi:10.1027/1015-5759.23.3.141

Garnefski, N., Kraaij, V., \& Spinhoven, P. (2001). Negative life events, cognitive emotion regulation and emotional problems. Personality and Individual Differences, 30, 1311-1327.

Goldin, P., Ziv, M., Jazaieri, H., Werner, K., Kraemer, H., Heimberg, R. G., \& Gross, J. J. (2012). Cognitive reappraisal self-efficacy mediates the effects of individual cognitive-behavioral therapy for social anxiety disorder. Journal of Consulting and Clinical Psychology, 80(6), 1034-1040. doi: $10.1037 / \mathrm{a} 0028555$

Gross, J. J., \& Muñoz, R. F. (1995). Emotion regulation and mental health. Clinical Psychology: Science and Practice, 2, 151-164.

Jermann, F., Van der Linden, M., d'Acremont, M., \& Zermatten, A. (2006). Cognitive Emotion Regulation Questionnaire (CERQ): Confirmatory factor analyses and psychometric properties of the French translation. European Journal of Psychological Assessment, 22, 126-131. doi: 10.1027/1015-5759.22.2.126

Jöreskog K. G., \& Sörbom D. (1996). LISREL 8: User's reference guide. Chicago, IL: Scientific Software International.

Kraaij, V., Garnefski, N., de Wilde, E. J., Dijkstra, A., Gebhardt, W., Maes, S., \& ter Doest, L. (2003). Negative life events and depressive symptoms in late adolescence: Bonding and cognitive coping as vulnerability factors. Journal of Youth and Adolescence, 32, 185-193.

Kruyen, P. M. (2012). Using Short Tests and Questionnaires for Making Decisions about Individuals: When is Short too Short? Ridderkerk (The Netherlands): Ridderprint BV.

Kruyen, P. M., Emons, W. H. M., \& Sijtsma, K. (2013). On the shortcomings of shortened tests: A literature review. International Journal of Testing, 13, 223-248. doi:10.1080/15305058.2012.703734
Miguel-Tobal, J. J., Casado, M. I., Cano-Vindel, A., \& Spielberger, C. D. (2001). State-Trait Anger Expression Inventory. Staxi-2. Madrid, España: TEA.

Sakakibara, R., \& Kitahara, M. (2016). The relationship between Cognitive Emotion Regulation Questionnaire (CERQ) and depression, anxiety: Meta-analysis. The Japanese Journal of Psychology, 87, 179-185.

Sandín, B., Chorot, P., Lostao, L., Joiner, T., Santed, M., \& Valiente, R. (1999). The PANAS scales of positive and negative affect: Factor analytic validation and cross-cultural convergence. Psicothema, 11, 37-51.

Scherer, K. R. (2009). The dynamic architecture of emotion: Evidence for the component process model. Cognition and Emotion, 23(7), 1307-1351. doi:10.1080/02699930902928969

Shadish, W. R., Cook, Th. D., \& Campbell, D. T. (2002). Experimental and quasi-experimental designs for generalized causal inference. New York: Houghton Mifflin.

Spielberger, C. D. (1988). Stait-Trait Anger Expression Inventory. Orlando, FL: Psychological Assessment Resources.

Spielberger, C. D., Gorsuch, R. L., \& Lushene, R. E. (1970). Manual for the State/Trait Anxiety Inventory. Palo Alto, CA: Consulting Psychologist Press.

Thompson, R. A. (1991). Emotional regulation and emotional development. Educational Psychology Review, 3, 269-307.

Vázquez, C., \& Sanz, J. (1997). Reliability and norm data of the Spanish version of the 1978 Beck Depression Inventory. Clinica y Salud, 8, 403-422.

Watson, D., Clark, L., \& Tellegen, A. (1988). Development and validation of brief measures of positive and negative affect: The PANAS scales. Journal of Personality and Social Psychology, 54, 1063-1070.

Yang-Wallentin, F., Jöreskog, K., \& Luo, H. (2010). Confirmatory factor analysis of ordinal variables with misspecified models. Structural Equation Modeling: A Multidisciplinary Journal, 17, 392-423. doi:10.1080/10705511.2010.489003.

Zhu, X., Auerbach, R. P., Yao, S., Abela, J. R. Z., Xiau, J., \& Tong, X. (2008). Psychometric properties of the Cognitive Emotion Regulation Questionnaire: Chinese version. Cognition and Emotion, 22, 288-307. doi:10.1080/02699930701369035

(Article received: 12-10-2017; revised: 23-03-2018; accepted: 20-04-2018) 